\title{
Rare case of leiomyoma in Mayer-Rokitansky-Kuster-Hauser syndrome
}

\author{
Sonal A. Bhuyar* \\ Department of Obstetrics \& Gynecology, Panjabrao Deshmukh Memorial Medical College, Amravati, Maharashtra, \\ India
}

Received: 16 April 2014

Accepted: 4 May 2014

*Correspondence:

Dr. Sonal A. Bhuyar,

E-mail: drsonalbhuyar14@gmail.com

(C) 2014 Bhuyar SA. This is an open-access article distributed under the terms of the Creative Commons Attribution Non-Commercial License, which permits unrestricted non-commercial use, distribution, and reproduction in any medium, provided the original work is properly cited.

\begin{abstract}
Mayer-Rokitansky-Kuster-Hauser (MRKH) syndrome is a cause for primary amenorrhea. It is characterized by the presence of XX karyotype, normal ovarian function and blind vaginal pouch. The uterus is usually represented by bilateral rudimentary primordia. Presence of functioning endometrial tissue may lead to development of hematometra in one or both primordia. Rarely myomas, neoplasms and adenomyosis can develop in the rudimentary bulbs. MRKH syndrome is frequently associated with urologic and skeletal abnormalities. In this case, a 45 year old patient presented with primary amenorrhea and lower abdominal pain. On examination, she had a blind vaginal pouch and a pelvic mass. She was investigated and taken for laparotomy with a provisional diagnosis of hematometra or ovarian tumor. The mass turned out to be leiomyoma in one of the rudimentary bulbs which was confirmed on histopathology. Our patient had vertebral abnormalities too. The incidence of MRKH syndrome is less and its association with pelvic tumor is even rarer. Hence this case is reported.
\end{abstract}

Keywords: Mullerian dysgenesis, Leiomyoma

\section{INTRODUCTION}

Mayer-Rokitansky-Kuster-Hauser syndrome (Mullerian dysgenesis) is a cause of primary amenorrhea, second in frequency only to gonadal dysgenesis. According to American fertility society classification, it is included in class I uterovaginal anomaly ${ }^{1}$ and is characterized by presence of 46XX karyotype, female secondary sexual characters, normal ovarian function including cyclic ovulation and undeveloped vagina. The uterus is usually represented by bilateral rudimentary primordia with no reproductive potential. Incidence of Mullerian agenesis is 1 in 4500 females with $\mathrm{XX}$ chromosomes ${ }^{2}$ and leiomyoma in uterine anlagen is even rarer.

\section{CASE REPORT}

A 45 year old married nulligravida presented in Dr. PDMMC hospital with complaints of primary amenorrhea and pain in right iliac fossa since 15 days.
The pain was not cyclical. Her physical examination showed a female body contour and normal breast development and hair pattern. Thyroid was not enlarged and there was no galactorrhoea. On abdominal examination, no abnormality was detected. The external genitalia were normal. Speculum examination revealed a blind $3 \mathrm{~cm}$ deep vaginal pouch and absent cervix. On bimanual examination, a solid mass of size $6 \times 6 \mathrm{~cm}$ was palpated immediately above vaginal pouch which was not freely mobile and was minimally tender. Rectal examination confirmed same findings.

Her preoperative profile was within normal limits. USG abdomen and pelvis was suggestive of solid hypoechoic mass of size $6.7 \times 5.7 \mathrm{~cm}$ in pelvic region. Uterus and cervix could not be visualized. Right ovary was not delineated, left ovary was normal. IVP suggested normal functioning of both kidneys, but also showed spina bifida at L5 vertebra with lateral wedging of L5 more on left side, probably a congenital defect. 
With a provisional diagnosis of MRKH Syndrome associated with hematometra in uterine anlagen or solid ovarian tumor, she was taken for laparotomy. Intra operative findings were suggestive of right sided horn of uterus enlarged with solid mass upto $6 \times 6 \mathrm{~cm}$ with tube and ovary adherent to the posterior aspect of the mass. Left horn was rudimentary with normal tube and ovary. Cervix and upper two-thirds of vagina was absent. Right sided supports of uterus were clamped, cut and ligated. After pushing the bladder down, clamps were applied beneath the mass and enlarged horn with tube and ovary was removed. Left horn with adnexa was preserved. She had an uneventful recovery and was discharged on $7^{\text {th }}$ post-operative day.

Cut section of specimen showed typical whorled appearance with a small slit like endometrial cavity pushed to one side suggestive of leiomyoma in that horn which was confirmed on histopathological examination.

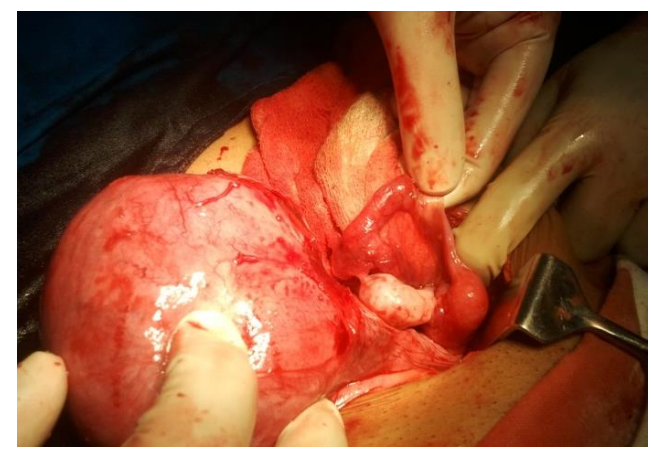

Figure 1: Leiomyoma in one horn and other horn rudimentary with normal adnexa.

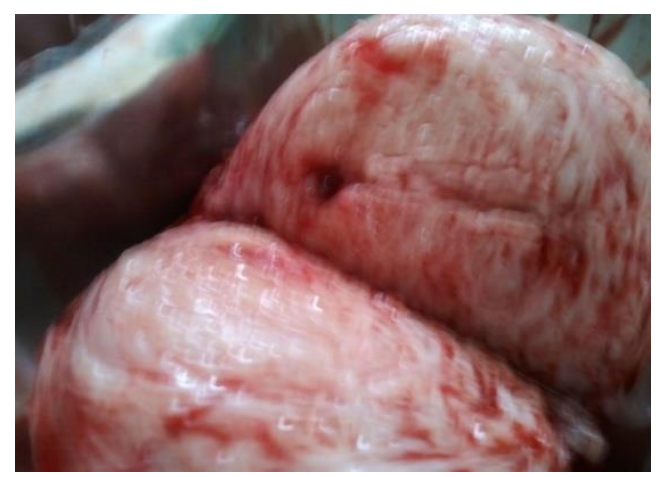

Figure 2: Cut section of specimen showing typical whorled pattern and a slit like endometrial cavity.

\section{DISCUSSION}

MRKH syndrome is characterized by absent or undeveloped uterus and upper part of the vagina. Failure of fusion and development of Mullerian ducts results in muscular thickening at the proximal end of each tube that are joined in the midline by a visible and palpable cord resembling hypoplastic bicornuate uterus without an endometrial lining. ${ }^{3}$ Rarely, an active endometrium can exist with uterine anlage, which becomes active in the presence of well estrogenised state.

Reports have described patients with functioning endometrial tissue or even a hematometra in one or both of the rudimentary uterine horns. ${ }^{3}$ As ovarian function is normal, estrogen dependent pathological conditions can develop in the rudimentary uterus, including myomas ${ }^{4}$, neoplasms and adenomyosis. ${ }^{4,5}$

The exact pathogenesis of neoplastic transformation of uterine smooth muscle in a patient with normal uterus is not known. Cytogenetic abnormalities in the form of spontaneous_chromosomal rearrangements are known to occur in uterine leiomyomas. These chromosomal arrangements may be responsible for the initiation and progressive growth of the leiomyomas. As the proximal ends of Mullerian ducts have smooth muscles, the presence of myoma in a case of Mullerian agenesis is a theoretical possibility. ${ }^{6}$ However occurrence of leiomyoma in a rudimentary uterine bulb has been rarely reported. The possible reason for this uncommon occurrence could be a decreased concentration or sensitivity of the estrogen receptors.

$47 \%$ of patients with Mullerian agenesis are associated with significant urologic abnormalities, including unilateral renal agenesis, unilateral or bilateral pelvic kidneys, horseshoe kidney, hydroureter, hydronephrosis and ureteral duplication. ${ }^{7}$ There is a $12 \%$ incidence of skeletal abnormalities, including spine (wedge vertebra, fusions, rudimentary or supernumerary vertebrae), limbs (syndactyly, absence of digit) and ribs. ${ }^{8}$ Our patient too had spina bifida with wedged L5 vertebra.

\section{CONCLUSION}

Although myoma arising from a rudimentary uterine anlage is a rare finding, it should be considered in the differential diagnosis of pelvic mass in patients with MRKH syndrome.

\section{Funding: No funding sources Conflict of interest: None declared Ethical approval: Not required}

\section{REFERENCES}

1. American Fertility Society. Classification of mullerian anomalies. Fertil Steril. 1988;49:952.

2. Karine M, Laure C, Daniel G. Mayer-RokitanskyKüster-Hauser (MRKH) syndrome. Orphanet J Rare Dis. 2007;2:13.

3. Rock JA, Baramki TA, Parmley TH et al. A unilateral functioning uterine analge with mullerian duct agenesis. Int J Gynecol Obstet. 1980;18:99-101.

4. Parikh MN. Congenital absence of vagina: MRKH syndrome. J Obstet Gynecol. 2000;50(5):128-30.

5. Enatsu A, Hasada T, Yoshida $\mathrm{S}$ et al. Adenomyosis in a patient with the Rokitansky-Kuster-Hauser syndrome. Fertil Steril. 2000 Apr;73:862-3. 
6. Rein MS, Friedman AJ, Barbieri RL et al. Cytogenetic abnormalities in uterine leiomyomata. Obstet Gynecol. 1991;77:923-6.

7. Fore SR et al. Urologic and genital anomalies in patients with congenital absence of vagina. Obstet Gynecol. 1975;46:410.
8. Griffin JE et al. Congenital absence of the vagina. Ann Intern Med. 1976;85:224.

DOI: $10.5455 / 2320-1770 . i j r \operatorname{cog} 20140647$

Cite this article as: Bhuyar SA. Rare case of leiomyoma in Mayer-Rokitansky-Kuster-Hauser syndrome. Int J Reprod Contracept Obstet Gynecol 2014;3:488-90. 